Prepared for the U.S. Department of Energy

under Contract DE-AC05-76RL01830

\title{
Handling Pyrophoric Reagents
}

MS Alnajjar TO Haynie

August 2009

Pacific Northwest

NATIONAL LABORATORY

Proudly Operated by Battelle Since 1965 


\section{DISCLAIMER}

This report was prepared as an account of work sponsored by an agency of the United States Government. Neither the United States Government nor any agency thereof, nor Battelle Memorial Institute, nor any of their employees, makes any warranty, express or implied, or assumes any legal liability or responsibility for the accuracy, completeness, or usefulness of any information, apparatus, product, or process disclosed, or represents that its use would not infringe privately owned rights. Reference herein to any specific commercial product, process, or service by trade name, trademark, manufacturer, or otherwise does not necessarily constitute or imply its endorsement, recommendation, or favoring by the United States Government or any agency thereof, or Battelle Memorial Institute. The views and opinions of authors expressed herein do not necessarily state or reflect those of the United States Government or any agency thereof.

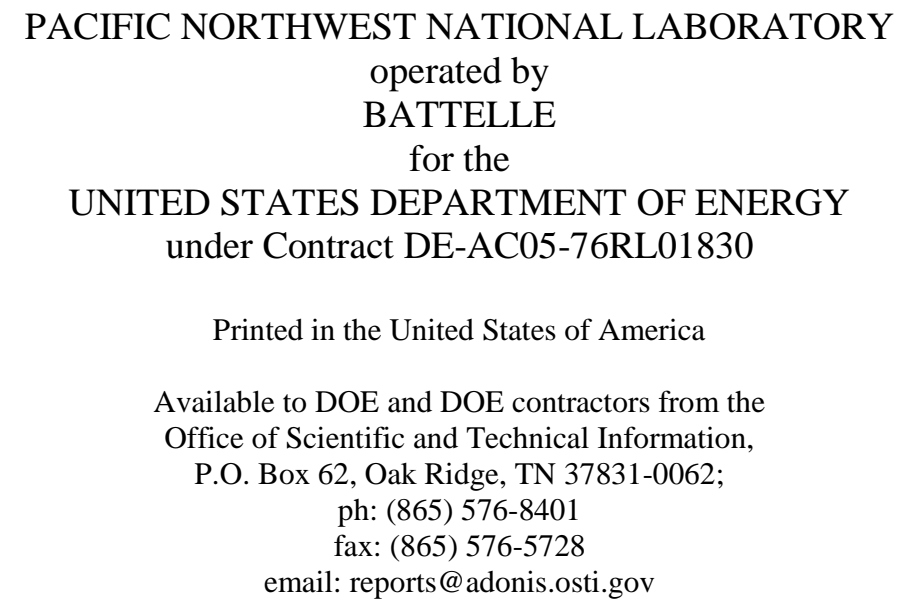

Available to the public from the National Technical Information Service, U.S. Department of Commerce, 5285 Port Royal Rd., Springfield, VA 22161 ph: (800) 553-6847 fax: (703) 605-6900

email: orders@ntis.fedworld.gov

online ordering: http://www.ntis.gov/ordering.htm 


\title{
Handling Pyrophoric Reagents
}

\author{
MS Alnajjar \\ TO Haynie
}

August 2009

Prepared for

the U.S. Department of Energy

under Contract DE-AC05-76RL01830

Pacific Northwest National Laboratory

Richland, Washington 99352 



\section{Contents}

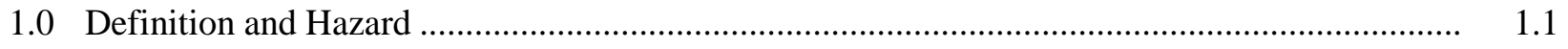

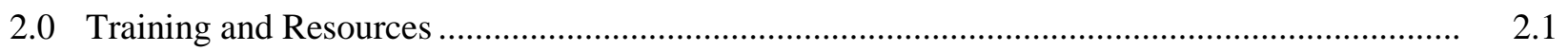

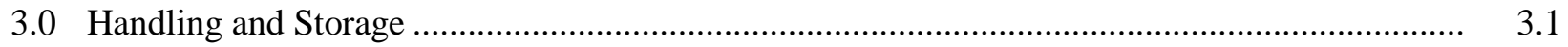

3.1 Pyrophoric Solids ................................................................................................. 3.1

3.1.1 Key Elements for Handling Pyrophoric Solids ................................................... 3.1

3.1.2 Working with Pyrophoric Reagents Inside the Inert Atmosphere of a Glovebox..... 3.2

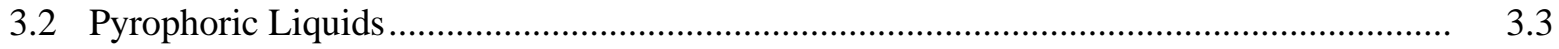

3.2.1 Transferring Liquid Pyrophoric Reagents Outside the Inert Atmosphere of a

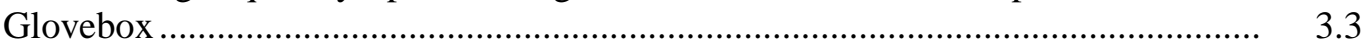

3.2.2 When a Syringe is used, the Best Practice for transferring a pyrophoric reagent is shown in Method A below

3.2.3 When a Double-Tipped Needle is used, the Best Practices for transferring pyrophoric reagents are shown in Methods B or C................................................. 3.5

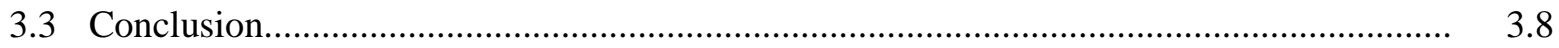

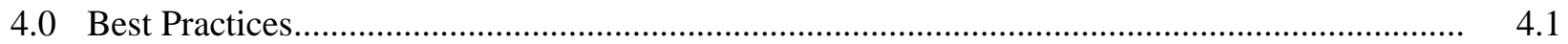

5.0 Additional Information ........................................................................................................ 


\section{Figures}

Figure 3.1. Syringe Transfer Assembly Equipped with an Inert Gas Line and a Bubbler during Reagent Transfer

Figure 3.2. Double-Tipped Needle Assembly Equipped with a Bubbler and Kept Under an Inert

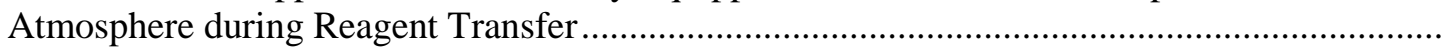

Figure 3.3. Double-Tipped Needle Assembly Equipped with a Vacuum Pump and Kept Under an Inert Atmosphere during Reagent Transfer.

Figure 4.1. Syringe Transfer Assembly with Inert Gas Line (1), Bubbler (2), Secure Reagent Bottle (3), and Fire Resistant Gloves

Figure 4.2. Transfer Assembly in Fume Hood with Researcher in Proper PPEs.. 


\subsection{Definition and Hazard}

Pyrophoric reagents are substances that ignite instantly upon exposure to oxygen, and in most cases are also water-reactive, where heat and hydrogen (flammable gas) are produced. For example, tertiarybutyllithium ( $t$-BuLi), and a variety of alkyllithium derivatives, will catch fire if exposed to air at modest humidity. Failure to follow proper handling techniques could result in serious injury or even death to the person handling the materials or to others in close proximity.

Although there are some pyrophoric gases, most pyrophoric reagents fall into the category of solid, pure liquid, or a solution. Examples of pyrophoric reagents are metal hydrides, finely divided metal powders, nonmetal hydride and alkyl compounds, white phosphorus, alloy of reactive metals, and selected organometallic compounds; including alkyllithiums.

Most of pyrophoric reagents fall into the following categories:

- Alkyl aluminum reagents

- Alkyl lithium reagents

- Alkyl zinc reagents

- Alkylphosphines

- Alkylsilanes

- Metal hydrides

- Iron pentacarbonyl

- Sodium/Potassium Alloy (NaK). 



\subsection{Training and Resources}

Pyrophoric reagents should be handled only by those with experience in their hazards and properties. Users with limited experience must be trained on how to handle pyrophoric reagents and consult with a knowledgeable staff member (supervisor or colleague) prior to performing the experimental task. $A$ knowledgeable staff member is a person who has prior experience in handling pyrophoric reagents and is aware of their properties and the hazards associated with their manipulation. Users must also read the manufacturer's MSDSs and understand the technical information associated with handling the materials. 



\subsection{Handling and Storage}

When storing a bottle of pyrophoric reagent for a long period of time after the initial use, the integrity of the reagent may be compromised. For example, the concentration of a solution of $t$-butyllithium may be higher or lower than what is given on the label; higher from solvent evaporation or lower from decomposition due to air/water infiltration. Therefore, it is highly recommended that pyrophoric reagents are purchased in quantities that will be used in each experiment to avoid the storage of excessive amounts of these hazardous chemicals. If storage is needed, make sure that the head space above the reagent is purged with an inert gas before storage.

Neutralization of excess reagents should be done carefully. When a syringe or a double-tipped needle (cannula) is used in handling pyrophoric reagents, the assembly should be rinsed with an inert (nonreacting) solvent and the rinse transferred to a flask under an inert atmosphere for subsequent neutralization. Since waste packaging and disposal requirements may change, contact your organization's waste management group for assistance prior to neutralization and disposal of excess reagents.

\subsection{Pyrophoric Solids}

Although pyrophoric solids are more stable to air than pyrophoric liquids, caution must be exercised during handling, storage, and disposal. In general, pyrophoric reagents are usually handled in a glovebox or Schlenk line under an inert gas. Some pyrophoric solids, such as lithium and sodium, are sold as dispersions in mineral oil to reduce the rate of oxidation to oxides/hydroxides and the pyrophoric character of the reagents. Removal of the mineral oil is accomplished by cutting a piece of the alkali metal and transferring it to a flask containing a hydrocarbon solvent such as hexane to rinse off the oil. Other mildly pyrophoric solids, such as dispersions in oil of sodium hydride (NaH) and lithium aluminum hydride $\left(\mathrm{LiAlH}_{4}\right)$, can be handled in air for short periods of time. The dry solid forms should be handled under inert atmosphere. In addition, the containers must be kept under a blanket of inert gas during storage.

Caution: If sodium amalgam $(\mathrm{Na}[\mathrm{Hg}])$ needs to be prepared and used, use extreme caution. Dissolving sodium into liquid mercury results in a very exothermic reaction; producing the intermetallic compound $\mathrm{NaHg}_{2}$ with enough heat to cause localized boiling of the mercury. The preparation of sodium amalgam should be performed in a hood under an inert atmosphere. The benefit of obtaining sodium amalgam is that it has the reducing potential of sodium, a larger surface area, and is more air stable.

Note: Potassium metal is more reactive than lithium and sodium. During prolonged storage, potassium can be oxidized to form a potassium superoxide $\left(\mathrm{KO}_{2}\right)$ coating; a yellow, shock-sensitive peroxide that can explode on handling.

\subsubsection{Key Elements for Handling Pyrophoric Solids}

- In case of emergency, call your emergency contact, building manager, and your immediate manager.

- Many pyrophoric solids release flammable and harmful gases. Therefore, handling these chemicals in a fume hood, using engineering controls and proper personal protective equipment 
(i.e., fire resistant lab coat and gloves), is required to reduce the release of vapors in the laboratory, eliminate skin contact with the chemical, and prevent injuries.

- Store pyrophoric solids under an inert atmosphere and avoid areas of heat, oxidizers, flammable solvents, and water sources. To avoid uncontrollable ignition, do not leave containers with residues of pyrophoric materials open to the atmosphere.

- All containers must be labeled appropriately with the chemical name and hazard warning.

- Make sure that the pyrophoric residues in empty containers, spatulas, and other contaminated items are carefully quenched before disposal. After significant dilution of the residues with a nonreacting solvent under an inert atmosphere, place a cooling bath (dry ice/acetone) under the reaction vessel to dissipate the heat, and slowly add isopropyl alcohol to quench the materials.

- Do not cut pieces of sodium metal or other active metals on paper towels or other combustible materials and do not clean up residues from these procedure using paper towels, unless the reactive materials have positively been quenched. A common problem is subsequent ignition when these contaminated towels are disposed into waste receptacles.

- Slowly add methanol followed by copious amount of water (stronger neutralization agent) to complete the quenching.

- In case of a small spill (controllable) during the quenching or transfer of the pyrophoric solid, smother the spill with compatible materials or dry sand, place a fire extinguisher nearby, and mark-off the area with warning signs. Call your emergency contact, building manager, and immediate manager. Collect the mixture and quench as stated above before disposal.

- In case of a large spill (uncontrollable) during the quenching or transfer of the pyrophoric solid, warn others to leave, and pull the fire alarm, call your emergency contact, building manager, and immediate manager.

- Provide emergency personnel with technical information about the chemical; if needed.

- Contact your organization's waste management group for assistance with disposal

\subsubsection{Working with Pyrophoric Reagents Inside the Inert Atmosphere of a Glovebox}

Pyrophoric reagents (liquids or solids) are easily manipulated under the inert atmosphere of an efficient glovebox. Therefore, it is highly recommended that reagents (liquids or solids) be used whenever possible within the confines of the glovebox or equivalent. Caution must be exercised when removing pyrophoric contaminated glassware, wipes, spatulas, gloves, or septa from the glovebox. When possible, the contaminated equipment should be neutralized inside the glovebox prior to removal. However, if this cannot be accomplished, the equipment should be brought out of the glovebox in a container under an inert atmosphere, connected to an inert gas line, and neutralized as appropriate.

Note: Under certain conditions, nitrogen reacts exothermically with lithium metal and some organometallic compounds. For this reason, the use of argon as the inert atmosphere is usually advisable if you are uncertain about the reactivity of the reagent with nitrogen. 


\subsection{Pyrophoric Liquids}

\subsubsection{Transferring Liquid Pyrophoric Reagents Outside the Inert Atmosphere of a Glovebox}

If an inert atmosphere glovebox is not available and a pyrophoric reagent such as t-butyllithium solution needs to be used, the solution can be transferred by either a syringe or double-tipped needle (cannula) outside the glovebox only if the transfer takes place under an inert atmosphere using proper handling techniques (see methods A-C below).

Important: The following list contains very key elements for transferring pyrophoric reagents outside the inert atmosphere of a glovebox.

- Do not work alone when handling pyrophoric reagents. Laboratory policy recommends that a colleague be present (the Buddy System) while working with hazardous chemicals. For example, if you become unable to respond to a situation due to an injury, the colleague can provide immediate assistance and make the calls to your emergency contact and building manager who can make the contact with your immediate manager.

- Fire-resistant apparel (PPE) and safety glasses must be worn at all times when working with pyrophoric reagents. Fire-retardant laboratory coats are mandatory, and fire-retardant gloves are highly recommended. Note: Fire resistant gloves can also absorb hazardous liquids and consideration should be given to using the gloves in conjunction with appropriate chemicallyresistant gloves. In other words, extreme caution must be exercised to mitigate skin exposure or spillage when handling pyrophoric reagents. Avoid wearing synthetic clothing while working with pyrophoric reagents as they do not provide the required protection. Natural fiber clothing tends to char instead of melt when exposed to flames or high temperatures and is preferable to synthetic fibers.

- Be prepared for the worst when handling pyrophoric reagents. These reagents can catch fire very easily when exposed to air. It is therefore advisable that extreme caution be used. Know the location of the safety shower, a blanket, a sand bucket, and how to use a fire extinguisher in case of emergency.

- If uncertain of how to handle pyrophoric reagents, users must consult a knowledgeable staff member prior to performing the experimental task, read the manufacturer's MSDSs, and understand the technical information associated with handling the materials.

- Perform the work inside a fume hood with the sash down as far as possible for protection against chemical splashes and unexpected ignition events.

- Remove all other flammable materials from the hood to reduce the hazard in case of a fire.

- Secure the pyrophoric reagent bottle to a stand with a clamp before use to prevent it from tipping over. Controlling the bottle with one hand while handling the syringe with the other hand is strongly discouraged.

- Use a long needle to reach the solvent level. Do not invert the bottle as such action dislodges sediments that may clog the needle. 
- Use a wide bore needle of 18-gauge or larger. The use of a smaller bore needle can slow down the transfer process and cause the needle to clog.

- Use a luer-lock syringe with long needle when possible and be sure that the assembly does not leak. Make sure that the needle is secured in the luer-lock and does not separate from the barrel during the transfer.

- When disposable plastic syringes are used, it is highly recommended that the transfer is performed within the confinement of a glovebox. The syringes must be rinsed with non-reacting solvent, neutralized as appropriate, and disposed of safely at the conclusion of the transfer.

- All equipment, such as syringes and glassware, should be free of moisture and purged with an inert gas prior to use.

- Slowly add the pyrophoric reagent to the reaction vessel in a cooling bath to control reaction rate and heat dissipation.

- A container with residual pyrophoric reagents must never be opened. The containers must be rinsed with inert solvent and neutralized with adequate cooling prior to disposal. If uncertain of how to safely neutralize residual pyrophoric reagents, consult with an experienced staff member prior to neutralization.

- Products from pyrophoric reagents should be handled as potentially highly-reactive materials.

- If a person is splashed with chemicals and catches fire, the use of the stop, drop, and roll method, safety shower, a fire blanket, or fire extinguisher $\left(\mathrm{H}_{2} \mathrm{O}, \mathrm{CO}_{2}\right.$ or $\left.\mathrm{A}, \mathrm{B}, \mathrm{C}\right)$ are the most effective means of controlling clothing on fire. If a safety shower is available, keep the person under the shower for at least 15-20 minutes to make sure that all chemicals are washed away. Call your emergency contact.

\subsubsection{When a Syringe is used, the Best Practice for transferring a pyrophoric reagent is shown in Method A below.}

Note: When a syringe is used, extreme caution must be exercised to prevent the plunger from separating from the syringe. Use luer-lock, airtight syringes for the transfer. Avoid the transfer of a large volume (> $10 \mathrm{~mL}$ ) from the pyrophoric reagent bottle when using syringes. For transferring larger volumes, used the double-tipped needle methods described below. At the conclusion of the transfer, the syringe needs to be clean to minimize the chance of the plunger from sticking/freezing in the barrel. The residue should be diluted with non-reacting solvent and remain under an inert atmosphere until rinsed with non-reacting solvent and the rinse and other residues are neutralized as appropriate.

\section{$\underline{\text { Method A }}$}

Figure 3.1 shows the complete assembly of reagent transfer using an airtight glass syringe and a bubbler, for pressure release, under an inert atmosphere. The volume of reagent to be transferred is not to exceed $10 \mathrm{~mL}$. See the Laboratory Safety Fact Sheet \#34 Pyrophoric Organolithium Reagents (PDF) for more information.

- Make sure that the syringe and the needle attached to the inert gas line needle, equipped with a bubbler and a shut-off valve, are purged prior to reagent transfer. 
- Insert the needle, connected to the inert gas line (bubbler), through the septum into the headspace above the reagent to maintain a slight positive pressure inside the Sure/SealTM pyrophoric reagent bottle.

- Insert the long needle of a luer-lock, airtight, dry syringe through the septum into the reagent.

- Pull the plunger back slowly to fill the syringe with the required volume of reagent. Always keep the plunger in your grasp and avoid pulling back the plunger quickly as this action causes leaks and creates gas bubbles.

- Once the required volume is attained, slowly pull up the syringe needle from the pyrophoric reagent to the overhead space above the liquid.

- Pull the plunger up slowly and allow the inert gas to push the reagent trapped in the needle into the syringe.

- Shut the inert gas line off and slowly pull the needle out from the assembly to complete the transfer.

- At the conclusion of the transfer, the syringe and needle need to be rinsed with a non-reacting solvent and the residue quenched as appropriate under an inert atmosphere (see above).

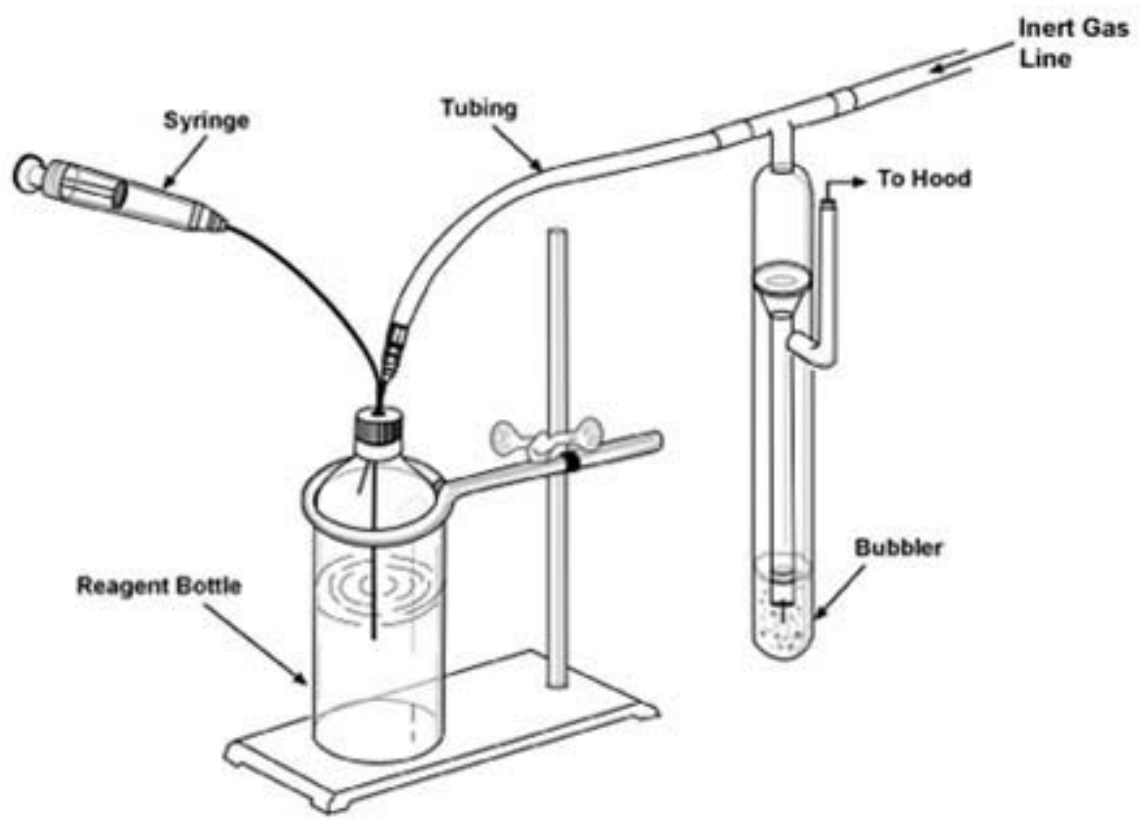

Figure 3.1. Syringe Transfer Assembly Equipped with an Inert Gas Line and a Bubbler during Reagent Transfer

\subsubsection{When a Double-Tipped Needle is used, the Best Practices for transferring pyrophoric reagents are shown in Methods $B$ or $C$.}

Note: At the conclusion of the transfer, the needle needs to be clean to minimize clogging. The residue should be diluted with non-reacting solvent and remain under an inert atmosphere until the rinse and other residues are neutralized as appropriate. 


\section{Method B}

Figure 3.2 shows the complete assembly for reagent transfer using a double-tipped needle under low pressure ( $<1 \mathrm{PSI}$ ) from an inert gas line. Note that a bubbler is connected to the reaction vessel to avoid pressure build up in the assembly. See the Laboratory Safety Fact Sheet \#34 Pyrophoric Organolithium Reagents (PDF) for more information.

- Make sure that the glassware being used is dry, and the assembly is purged and maintained under an inert atmosphere prior to reagent transfer.

- Insert one end of the double-tipped needle through the septum into the reaction vessel or addition funnel in order to flush the needle.

- Insert the other end of the double-tipped needle through the septum of the reagent bottle into the headspace above the liquid.

- A needle attached to a very low pressure inert gas line ( $<1$ PSI) is inserted through the septum into the headspace and kept above the solution of the Sure/Seal ${ }^{\mathrm{TM}}$ pyrophoric reagent bottle.

- Transfer the liquid from the reagent bottle into the reaction vessel or the addition funnel by pushing down the end of the double-tipped needle in the reagent bottle into the liquid.

Note: At all times during the transfer, the reaction vessel must be vented through a mineral oil bubbler and kept under a positive pressure of an inert atmosphere to prevent air from entering the system.

- $\quad$ Once the required volume is transferred, pull up slowly on the end of the double-tipped needle in the pyrophoric reagent so that it is no longer in the liquid, but still through the septum and in the headspace above the liquid. Allow the inert gas to flow through the needle to push the trapped reagent in the needle to reaction vessel or the addition funnel.

- At the conclusion of the transfer, the double-tipped needle needs to be rinsed with non-reacting solvent and the residue quenched as appropriate under an inert atmosphere (see above). 


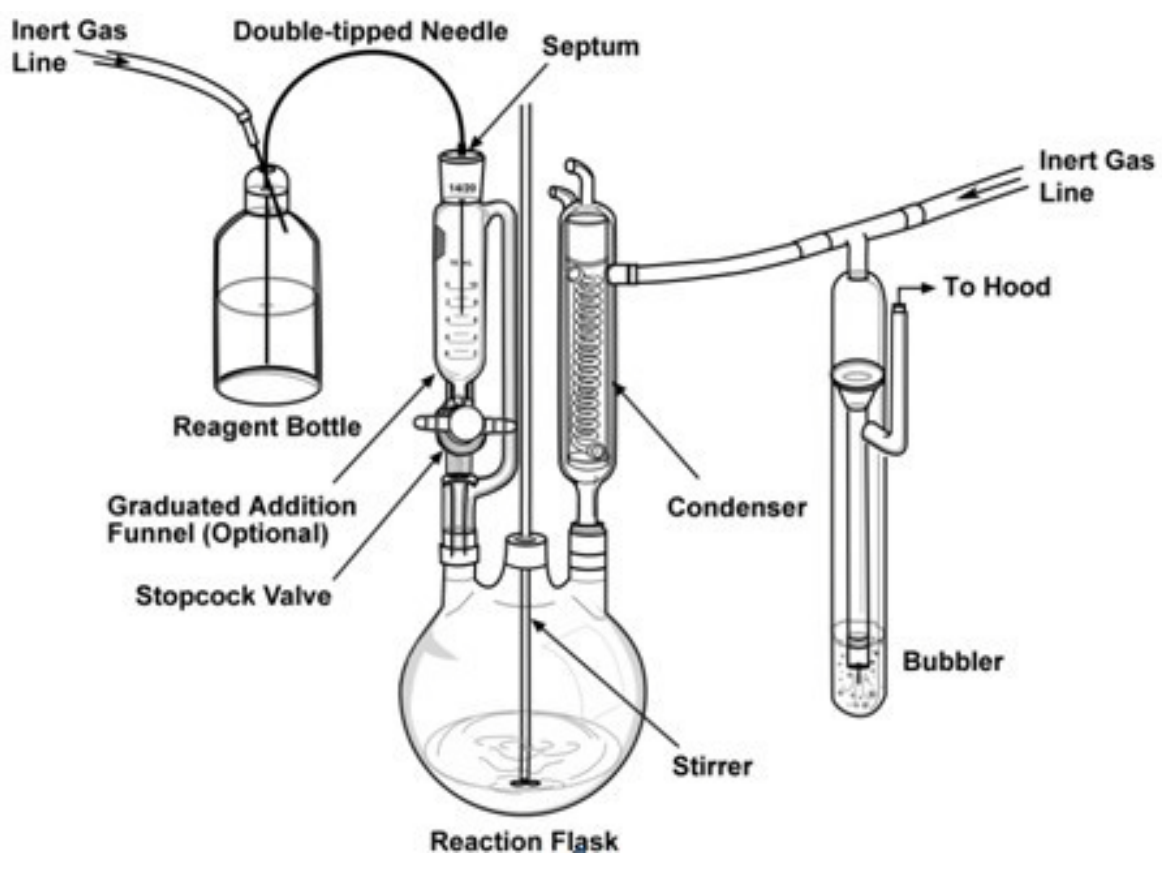

Figure 3.2. Double-Tipped Needle Assembly Equipped with a Bubbler and Kept Under an Inert Atmosphere during Reagent Transfer

\section{Method C:}

Figure 3.3 shows the complete assembly for reagent transfer using the double-tipped needle under slight vacuum and connected to an inert gas line through a bubbler.

- Make sure that the reaction vessel being used is dry, and that the assembly is purged and maintained under an inert atmosphere prior to reagent transfer.

- Insert the double-tipped needle through the septum into the reaction vessel or addition funnel to purge the needle with inert gas.

- Insert the other end of the double-tipped needle into the head space above the liquid of the pyrophoric reagent bottle.

- Connect a vacuum line with a shutoff valve to the reaction vessel (as shown below).

- Insert the needle connected to the inert gas line (bubbler) through the septum into the headspace of the Sure/SealTM reagent bottle to keep the space above the solution under a blanket of an inert gas.

- Make sure that the assembly is in proper configuration, and the inert gas is flowing through the bubbler.

- $\quad$ Push the end of the double-tipped needle in the reagent bottle down into the pyrophoric reagent.

- Apply a slight vacuum to the reaction vessel assembly by opening the vacuum valve slowly to transfer the desired volume from the reagent bottle to the reaction vessel through the doubletipped needle.

Caution: The vacuum line will only need to be opened intermittently in order to transfer the 
pyrophoric reagent. High and continuous vacuum may allow air to enter the system through the bubbler.

- $\quad$ Once the required volume is transferred, pull up slowly on the end of the double-tipped needle in the pyrophoric reagent so that it is no longer in the liquid, but still through the septum and in the headspace above the liquid. Allow the inert gas to flow through the double-tipped needle to push the trapped reagent in the needle to reaction vessel.

- Close the vacuum valve and connect the reaction flask to an inert gas line.

- At the conclusion of the transfer, the double-tipped needle needs to be rinsed with non-reacting solvent and the residue quenched as appropriate under an inert atmosphere (see above).

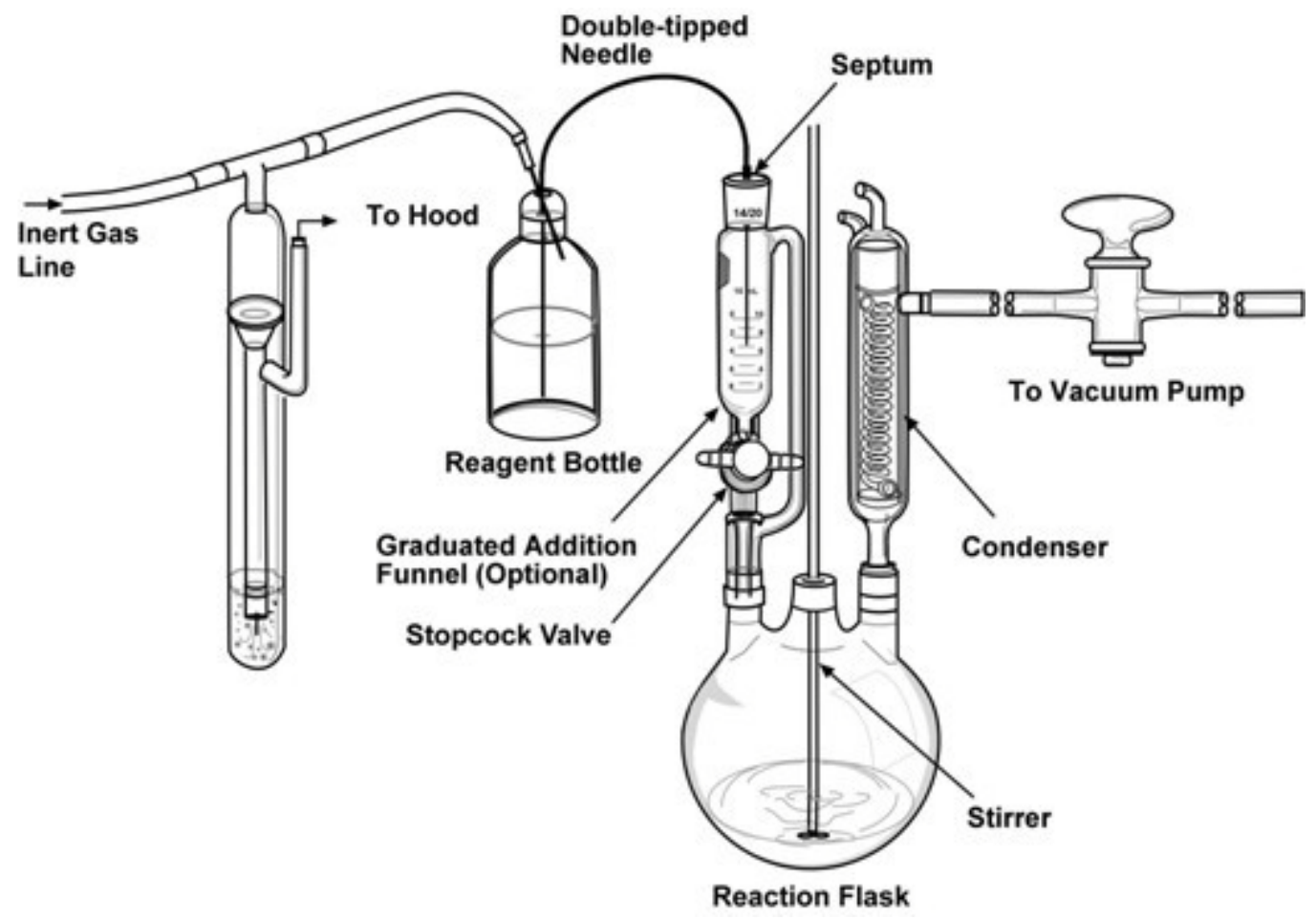

Figure 3.3. Double-Tipped Needle Assembly Equipped with a Vacuum Pump and Kept Under an Inert Atmosphere during Reagent Transfer

\subsection{Conclusion}

Caution must be exercised at all times when dealing with pyrophoric reagents. The ways to minimize or prevent injuries from handling such reagents and other hazardous materials are through proper training, vigilance, complying with regulatory requirements, and following safety guidelines and procedures in the workplace. 


\subsection{Best Practices}

Figures 4.1 and 4.2 contain very key elements for transferring pyrophoric reagents outside an inert atmosphere of a glovebox using an airtight glass syringe.

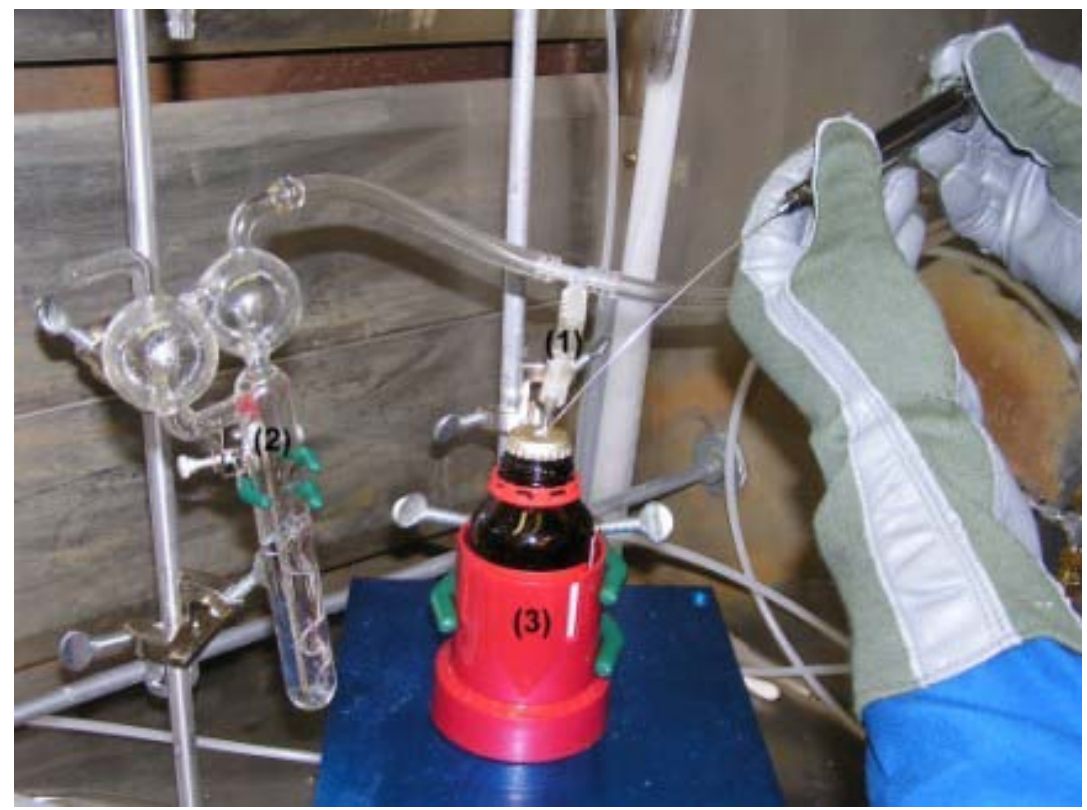

Figure 4.1. Syringe Transfer Assembly with Inert Gas Line (1), Bubbler (2), Secure Reagent Bottle (3), and Fire Resistant Gloves

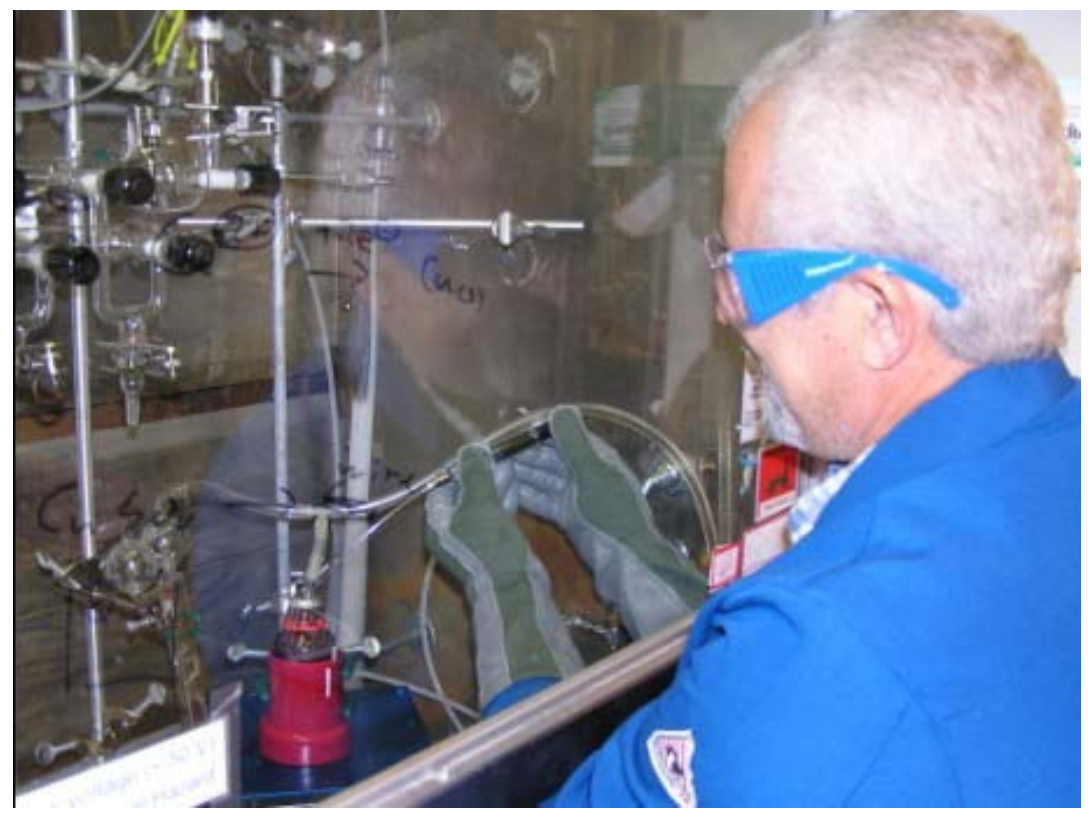

Figure 4.2. Transfer Assembly in Fume Hood with Researcher in Proper PPEs 



\subsection{Additional Information}

The links below provide access to additional information about handling pyrophoric chemicals.

- $\quad$ Brandeis University, Pyrophoric Chemicals

- $\quad$ Safe Handling of Organolithium Compounds in the Laboratory (PDF)

- $\quad$ University of Rochester, SOP for Pyrophoric Chemicals

- Sigma-Aldrich Bulletin - AL-134: Handling Air-Sensitive Reagents (PDF) (Warning: Avoid the use of Figure 8 shown in this bulletin.) 




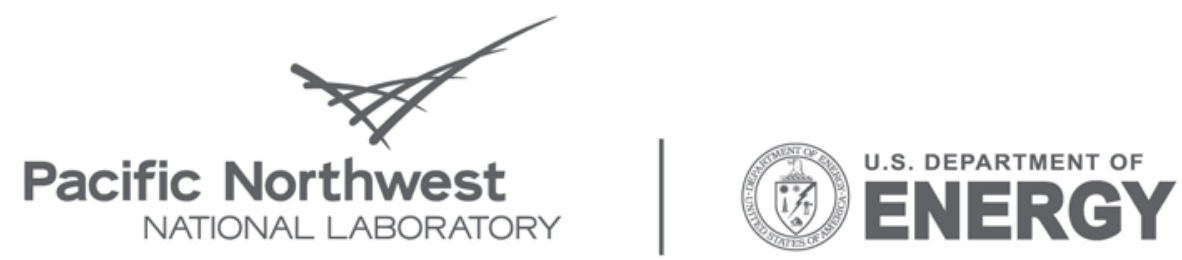

Proudly Operated by Battelle Since 1965

902 Battelle Boulevard

P.O. Box 999

Richland, WA 99352

1-888-375-PNNL (7665)

www.pnl.gov 